\title{
Regulation of cytosolic prostaglandin E synthase by phosphorylation
}

\author{
Tsuyoshi KOBAYASHI ${ }^{*}$, Yoshihito NAKATANI*, Toshihiro TANIOKA* $\dagger$, Masafumi TSUJIMOTO $\dagger$, Shigeo NAKAJO $\ddagger$, \\ Kazuyasu NAKAYA $\ddagger$, Makoto MURAKAMI* and Ichiro KUDO*1 \\ *Department of Health Chemistry, School of Pharmaceutical Sciences, Showa University, 1-5-8 Hatanodai, Shinagawa-ku, Tokyo 142-8555, Japan, † Laboratory of Cellular \\ Chemistry, RIKEN, 2-1 Wako-shi, Saitama 351-0198, Japan, and łLaboratory of Biological Chemistry, School of Pharmaceutical Sciences, Showa University, \\ 1-5-8 Hatanodai, Shinagawa-ku, Tokyo 142-8555, Japan
}

\begin{abstract}
cPGES [cytosolic PG (prostaglandin) E synthase] is constitutively expressed in various cells and can regulate COX (cyclo-oxygenase)-1-dependent immediate $\mathrm{PGE}_{2}$ generation. In the present study, we found that cPGES underwent serine phosphorylation, which was accelerated transiently after cell activation. Several lines of evidence suggest that a cPGES-activating protein kinase is CK-II (casein kinase II). Recombinant cPGES was phosphorylated directly by and associated with $\mathrm{CK}$-II in vitro, resulting in marked reduction of the $K_{\mathrm{m}}$ for the substrate $\mathrm{PGH}_{2}$. In activated cells, cPGES phosphorylation occurred in parallel with increased cPGES enzymic activity and $\mathrm{PGE}_{2}$ production from exogenous and endogenous arachidonic acid, and these processes were facilitated by Hsp90 (heat-shock protein 90), a molecular chaperone that formed a tertiary complex with cPGES and CK-II. Treatment of cells with inhibitors of CK-II and Hsp90 and with a
\end{abstract}

dominant-negative CK-II attenuated the formation of the cPGESCK-II-Hsp90 complex and attendant cPGES phosphorylation and activation. Mutations of either of two predicted CK-II phosphorylation sites on cPGES (Ser ${ }^{113}$ and $\mathrm{Ser}^{118}$ ) abrogated its phosphorylation and activation both in vitro and in vivo. Moreover, the CK-II-Hsp90-mediated activation of cPGES was ameliorated by the p38 mitogen-activated protein kinase inhibitor SB20358 or by the anti-inflammatory glucocorticoid dexamethasone. Taken together, the results of the present study have provided the first evidence that the cellular function of this eicosanoid-biosynthetic enzyme is under the control of a molecular chaperone and its client protein kinase.

Key words: arachidonic acid, molecular chaperone, phosphorylation, prostaglandin $\mathrm{E}_{2}$, prostaglandin $\mathrm{E}$ synthase.

\section{INTRODUCTION}

PG (prostaglandin) $E_{2}$ is the most common prostanoid that has potent and diverse bioactivities. Biosynthesis of $\mathrm{PGE}_{2}$ is regulated by three sequential steps of the COX (cyclo-oxygenase) pathway. cPLA $_{2}$ (cytosolic phospholipase $\mathrm{A}_{2}$ ) enzymes initiate this pathway by releasing AA (arachidonic acid) from membrane glycerophospholipids [1,2]. AA is then supplied to either of the two COX isoenzymes, COX-1 and COX-2, depending on the phase of cell activation [3-5]. COX-1, a constitutive COX isoenzyme, contributes mainly to immediate PG generation, which occurs within a few minutes after stimulation with $\mathrm{Ca}^{2+}$ mobilizers, whereas COX-2, an inducible enzyme, mediates delayed PG generation, which lasts for several hours following pro-inflammatory stimuli. The COX metabolite $\mathrm{PGH}_{2}$ is then isomerized to $\mathrm{PGE}_{2}$ by the terminal PGES (PGE synthase) enzymes.

Recent molecular identification of three PGES enzymes has opened new insights into the regulation of $\mathrm{PGE}_{2}$ biosynthesis [6-10]. Two of these are membrane-bound enzymes and have been designated mPGES-1 and mPGES-2 [6-9]. mPGES-1 is a glutathione-requiring perinuclear protein belonging to the MAPEG (for membrane-associated proteins involved in eicosanoid and glutathione metabolism) family [6-8]. This enzyme is markedly induced by pro-inflammatory stimuli, is downregulated by anti-inflammatory glucocorticoids, and is functionally coupled with $\mathrm{COX}-2$ in marked preference to COX-1 [11-16]. mPGES-2 has a glutaredoxin- or thioredoxin-like domain and is activated by various thiol reagents [9]. This enzyme is constitutively expressed in various cells and tissues and can be coupled with both COX-1 and COX-2 [17].

cPGES (cytosolic PGES) is a 23-kDa glutathione-requiring enzyme expressed constitutively in a wide variety of cells and tissues [10]. This enzyme can be functionally coupled with COX-1, but not COX-2, to promote immediate $\mathrm{PGE}_{2}$ production, leading to the suggestion that immediate and delayed $\mathrm{PGE}_{2}$-biosynthetic responses are respectively regulated by the constitutive COX-1/ cPGES and the inducible COX-2/mPGES-1 pathways $[8,10]$. However, the enzymic activity of recombinant cPGES produced by a bacterial expression system is rather low, leading us to hypothesize that mammalian cells may contain some accessory factors that can enhance cPGES activity. Indeed, we have recently identified Hsp90 (heat-shock protein 90), a molecular chaperone that forms a stable complex with cPGES in cells [18], to be one such factor.

In the present paper, we report that, in mammalian cells, cPGES undergoes phosphorylation, which leads to increase in cPGES catalytic function. This phosphorylation is mediated by CK-II (casein kinase II), a client protein for Hsp90 [19,20]. Transient formation of the tertiary complex comprising cPGES, CK-II and Hsp90 is required for phosphorylation and thereby optimal activation of cPGES in cells. Our results imply that cPGES is a unique eicosanoid-biosynthetic enzyme in that its cellular $\mathrm{PGE}_{2}$-biosynthetic function is facilitated after modification by a molecular chaperone and its client protein kinase.

Abbreviations used: AA, arachidonic acid; CaMK-II, Ca ${ }^{2+}$-calmodulin kinase II; CK-II, casein kinase II; COX, cyclo-oxygenase; DMEM, Dulbecco's modified Eagle's medium; DN, dominant-negative; DRB, 5,6-dichloro-1- $\beta$-D-ribofuranosylbenzimidazole; FCS, foetal calf serum; Hsp90, heat-shock protein 90; MAPK, mitogen-activated protein kinase; PG, prostaglandin; PGES, PGE synthase; cPGES, cytosolic PGES; mPGES, membrane-bound PGES; PKC, protein kinase $\mathrm{C}$; $c$ PLA 2 , cytosolic phospholipase $\mathrm{A}_{2}$; RT, reverse transcription; TBS, Tris-buffered saline; WT, wild-type.

1 To whom correspondence should be addressed (e-mail kudo@pharm.showa-u.ac.jp). 


\section{EXPERIMENTAL}

\section{Materials}

The mouse anti-(human Hsp90) antibody was purchased from Transduction Laboratories. The goat anti-(human CK-II $\alpha$ ) and anti-COX-1 antibodies and the rabbit anti-(human $\mathrm{cPLA}_{2}$ ) were purchased from Santa Cruz Biotechnology. AA, $\mathrm{PGH}_{2}$, and the enzyme immunoassay kits for $\mathrm{PGE}_{2}$ were from Cayman Chemicals (Ann Arbor, MI, U.S.A.). The CK-II inhibitor DRB (5,6dichloro-1- $\beta$-D-ribofuranosylbenzimidazole) and the calcium ionophore A23187 were purchased from Calbiochem. Bovine Hsp90, geldanamycin and bradykinin, indomethacin, the PKC (protein kinase C) inhibitor chelerythrine, the CaMK-II $\left(\mathrm{Ca}^{2+} /\right.$ calmodulin kinase II) inhibitor KN-93, the tyrosine kinase inhibitor genistein, dexamethasone, and the bradykinin receptor $\mathrm{B}_{2}$ antagonist HOE140 were purchased from Sigma. The p38 MAPK (mitogen-activated protein kinase) inhibitor SB20358 was obtained from Wako Pure Chemical Industries (Tokyo, Japan). Calf intestine alkaline phosphatase was from Takara Biomedicals (Osaka, Japan). Recombinant CK-II was purchased from PerkinElmer. Escherichia coli-derived recombinant cPGES protein and rabbit anti-human cPGES antibody were prepared as described previously [10]. Horseradish-peroxidase-conjugated secondary antibodies were purchased from Zymed Laboratories (San Francisco, CA, U.S.A.).

\section{Cell culture and activation}

Rat fibroblastic 3Y1 cells were cultured in DMEM (Dulbecco's modified Eagle's medium; Nissui Pharmaceutical Co., Tokyo, Japan) containing $10 \%$ (v/v) FCS (foetal calf serum), as described in [21]. The majority of PGES activity in this cell line is ascribed to cPGES, as reported previously [18]. Cells $\left(1.5 \times 10^{5}\right.$ cells in $5 \mathrm{ml}$ of culture medium) were seeded into 6-well plates (Iwaki Glass, Tokyo, Japan) and cultured for 3 days to subconfluency. The cells were then incubated with $10 \mu \mathrm{M}$ AA, $10 \mu \mathrm{M}$ A23187 or $10 \mu \mathrm{M}$ bradykinin in serum-free DMEM for appropriate periods. In order to assess AA release, the cells were incubated with $0.1 \mu \mathrm{Ci} / \mathrm{ml}$ of $\left[{ }^{3} \mathrm{H}\right] \mathrm{AA}\left(\mathrm{NEN}^{\mathrm{TM}}\right.$ Life Science Products, Boston, MA, U.S.A.) for $24 \mathrm{~h}$, washed and treated with or without agonists in serum-free medium, and the radioactivity that was released into the supernatant was counted. Portions of the supernatant were taken for measurement of $\mathrm{PGE}_{2}$ using the enzyme immunoassay kit. As required for the experiments, the cells were pre-treated with $1 \mu \mathrm{M}$ geldanamycin, $10 \mu \mathrm{M}$ chelerythrine, $0.4 \mu \mathrm{M} \mathrm{KN}-93$, various concentrations of genistein or DRB, $1 \mu \mathrm{M}$ dexamethasone, $10 \mu \mathrm{M}$ HOE140, $10 \mu \mathrm{M}$ SB20358 or vehicle for $5 \mathrm{~h}$, and then stimulated in their continued presence. PGES activity in cell lysates was measured by the assessment of the conversion of $\mathrm{PGH}_{2}$ into $\mathrm{PGE}_{2}$ as reported previously $[10,18]$.

\section{${ }^{32} \mathrm{P}$-labelling of $3 Y 1$ cells}

Cells were cultured for $4 \mathrm{~h}$ in $500 \mu \mathrm{l}$ of serum-free DMEM without phosphate (Invitrogen) containing $10 \%$ (v/v) FCS and $0.5 \mu \mathrm{Ci} / \mathrm{ml}$ of $\mathrm{H}_{3}{ }^{32} \mathrm{PO}_{4}$ (PerkinElmer) in 35 -mm-diameter dishes (Iwaki Glass). After activation with agonists (see above), the cells were washed with $10 \mathrm{mM}$ Tris/ $\mathrm{HCl}(\mathrm{pH} 7.4)$ containing $250 \mathrm{mM}$ sucrose and lysed in $500 \mu \mathrm{l}$ of a buffer composed of $20 \mathrm{mM}$ Tris/ $\mathrm{HCl}$ (pH 7.4), $150 \mathrm{mM} \mathrm{NaCl}, 1 \%$ Nonidet P40, $50 \mathrm{mM} \mathrm{NaF}, 10 \mu \mathrm{g} / \mathrm{ml}$ leupeptin, $10 \mu \mathrm{g} / \mathrm{ml}$ aprotinin, $20 \mathrm{mM}$ $\mathrm{Na}_{2} \mathrm{MoO}_{4}, 1 \mathrm{mM} \mathrm{Na} \mathrm{VO}_{4}$ and $1 \mathrm{mM} \mathrm{PMSF}$ at $4{ }^{\circ} \mathrm{C}$ for $30 \mathrm{~min}$. After centrifugation for $5 \mathrm{~min}$ at $6000 \mathrm{~g}$, the supernatants were used as cell lysates for immunoprecipitation.

\section{Immunoprecipitation}

Cell lysates were pre-incubated with $10 \mu$ l of Protein G-Sepharose (PerkinElmer) for $1 \mathrm{~h}$ at $4{ }^{\circ} \mathrm{C}$ to remove non-specific adsorption. The supernatants were incubated with $2 \mu \mathrm{g}$ of anti-cPGES antibody and $10 \mu \mathrm{l}$ of Protein G-Sepharose at $4{ }^{\circ} \mathrm{C}$ overnight. After centrifugation at $1000 \mathrm{~g}$ for $5 \mathrm{~min}$, the pellets were washed five times with Tris-buffered saline $[10 \mathrm{mM}$ Tris/ $\mathrm{HCl}(\mathrm{pH} 7.4)$ containing $150 \mathrm{mM} \mathrm{NaCl}$ ] and suspended in $20 \mu \mathrm{l}$ of sample buffer for SDS/PAGE. SDS/PAGE and immunoblotting were performed as described previously $[10,18]$.

\section{In vitro phosphorylation of cPGES}

Recombinant cPGES or its mutants were incubated for $30 \mathrm{~min}$ at $30{ }^{\circ} \mathrm{C}$ with recombinant $\mathrm{CK}$-II in the presence or absence of $\mathrm{Hsp} 90$ in $20 \mathrm{mM}$ Tris/ $\mathrm{HCl}(\mathrm{pH} 7.5)$ containing $50 \mathrm{mM} \mathrm{KCl}$, $10 \mathrm{mM} \mathrm{MgCl}$, $40 \mu \mathrm{M}$ ATP and $10 \mu \mathrm{Ci} / \mathrm{ml}$ of $\left.{ }^{32} \mathrm{P}\right]$ ATP (PerkinElmer). Aliquots of samples were taken for PGES enzyme assay, and after brief boiling, samples were applied to SDS/PAGE followed by autoradiography.

\section{Phospho-amino acid analysis}

Replicate immunoprecipitates resolved by SDS/PAGE were transferred on to PVDF membranes (Millipore) and the positions of cPGES were precisely excised. The pieces were incubated with $100 \mu \mathrm{l}$ of $6 \mathrm{M} \mathrm{HCl}$ for $1 \mathrm{~h}$ at $110^{\circ} \mathrm{C}$. The supernatants were collected, evaporated and mixed with trace amounts of L-phosphoserine, L-phosphothreonine and L-phosphotyrosine (Sigma). Then the samples were spotted on to TLC plates (Merck) and electrophoresed at $1500 \mathrm{~V}$ for $25 \mathrm{~min}$ at $\mathrm{pH} 1.9[2.5 \%(\mathrm{v} / \mathrm{v})$ methanoic acid and $7.8 \%(\mathrm{v} / \mathrm{v})$ ethanoic acid in water] in the first dimension and at $1300 \mathrm{~V}$ for $20 \mathrm{~min}$ at $\mathrm{pH} 3.5[5 \%(\mathrm{v} / \mathrm{v})$ ethanoic acid and $0.5 \%(\mathrm{v} / \mathrm{v})$ pyridine in water] in the second dimension. After drying, separated amino acids on the plates were visualized with ninhydrin spray at $80^{\circ} \mathrm{C}$ for $15 \mathrm{~min}$. Incorporation of ${ }^{32} \mathrm{P}$ into each amino acid was detected by autoradiography.

\section{Construction of cPGES mutants}

cDNAs for cPGES point mutants were constructed by the mismatched PCR method, as described previously [8]. The primers used were as follows: p23 sense primer, 5'-ATGCAGCCTGCTTCTGCAAAGTG-3'; S113A (Ser ${ }^{113} \rightarrow$ Ala mutant) sense primer, 5'-ATTAGACATGTCTTCATCTGAATCATC-3'; S118A sense primer, 5'-ATTAGCCATGTCTTCATCTGCATCATC-3'; Y14F sense primer, 5'-ATGCAGCCTGCTTCTGCAAAGTGGTACACGATCGAAGGGACTTTGTC-3'; p23 FLAG antisense primer, 5'-TTACTTGTCATCGTCGTCCTTGTAGTCCTCCAGATCTGGCATTTT-3'; S24G antisense primer, 5'-GACGGTAAGGATGTTAATG-3'; and S151G FLAG antisense primer, 5'-TTACTTGTCATCGTCGTCCTTGTAGTCCTCCAGATCTGGCATTTTTTCATCATCACCGTC-3'. To construct the S113A mutant, PCR was conducted with a set of p23 sense and S24G antisense primers (for forward strand) and with a set of S113G sense and p23 FLAG antisense primers (for reverse strand) using ExTaq polymerase (Takara Biomedicals) and cPGES cDNA in pCR3.1 (Invitrogen) as a template with 25 cycles of $95^{\circ} \mathrm{C}$ for $30 \mathrm{~s}, 57^{\circ} \mathrm{C}$ for $30 \mathrm{~s}$ and $72^{\circ} \mathrm{C}$ for $30 \mathrm{~s}$. The resulting forward and back strands were mixed, heated, annealed and subjected to a second PCR with p23 sense and p23 FLAG antisense primers under the same thermal conditions. The S118A mutant was constructed with a set of p23 sense and S24G antisense primers (for forward 
strand) and S118A sense and p23 FLAG antisense primers (for reverse strand) in a similar way. To construct the S151G mutant, PCR was carried out with a set of p23 sense and S151G FLAG antisense primers. To construct the Y14F mutant, PCR was carried out with a set of Y14F sense and p23 FLAG antisense primers. The resulting PCR products were subcloned into pCR3.1 vector with T4 DNA ligase (Invitrogen) and transformed into Top10F' supercompetent cells (Invitrogen). The plasmids were isolated and sequenced using a Taq cycle sequencing kit (Takara Biomedicals) and an autofluorometric DNA sequencer 310 Genetic Analyser (Applied Biosystems) to confirm the mutations.

\section{Bacterial expression of recombinant cPGES proteins}

The native and mutant cPGES cDNA inserts were subcloned into pET21c (Novagen) and transformed into E. coli BL21 (DE3) (Stratagene). The cells were cultured with $0.3 \mathrm{mM}$ IPTG (isopropyl $\beta$-D-thiogalactoside) to induce $\mathrm{His}_{6}$-tagged recombinant proteins. Bacterial cell pellets were lysed in $20 \mathrm{mM}$ Tris/ $\mathrm{HCl}$ (pH 8.0) containing $0.5 \mathrm{mM} \mathrm{NaCl}, 10 \%$ (v/v) glycerol and $6 \mathrm{M}$ guanidinium chloride with stirring for $30 \mathrm{~min}$ at room temperature $\left(22^{\circ} \mathrm{C}\right)$. After centrifugation at $15000 \mathrm{~g}$ for $30 \mathrm{~min}$ at $4{ }^{\circ} \mathrm{C}$, the resulting supernatants were applied to a nickel-nitrilotriacetic acid-agarose column (Qiagen), pre-equilibrated with $100 \mathrm{mM}$ $\mathrm{NiSO}_{4}$ at a flow rate of $10 \mathrm{ml} / \mathrm{h}$. After washing, the bound proteins were eluted with the same buffer containing 20-60 mM imidazole in a stepwise manner. The purity of the recombinant proteins was verified by SDS/PAGE followed by staining with Coomassie Brilliant Blue.

\section{Transfection studies}

Transfection of cDNAs into 3Y1 cells was performed by lipofection, as described previously $[10,18]$. The transfectants were cloned by limiting dilution in 96-well plates in culture medium containing $0.8 \mathrm{mg} / \mathrm{ml}$ geneticin (Invitrogen). After culture for 2-3 weeks, appropriate clones were expanded and used for subsequent experiments.

\section{Construction of DN (dominant-negative)-CK-II}

Total RNA from 3 Y1 cells was subjected to RT (reverse transcription), and the full-length CK-II $\alpha$ cDNA was PCR-amplified with ExTaq from the RT product with the CK-II 5'-primer 5'-ATGTCGGCACCCTGCCAAGCAG-3' and the CK-II $3^{\prime}$-primer 5'-TCATTACTGCTGAGCGCCAGCGGC-3'. To construct DNCK-II $\alpha$, in which $\mathrm{Asp}^{156}$, a residue critical for ATP binding [22], was replaced with alanine, the mismatched PCR method was used. The first PCR was conducted with a set of the CK-II 5'-primer and the D156A antisense primer 5'-GACATTATGCGGTTTCACGGCTCTG-3' (for forward strand) and with a set of the D156A sense primer 5'-CATGGGGATTATGCACAGAGCCGTG-3' and the CK-II 3'-primer (for reverse strand) using CK-II $\alpha$ cDNA as a template. Then the forward and reverse strands were mixed, heated, annealed and subjected to a second PCR with a set of the CK-II 5' - and 3'-primers. The resulting cDNA fragment was subcloned into pCR3.1 and the mutation was confirmed by sequencing. The plasmid with or without DN-CK-II $\alpha$ was then transfected into $3 \mathrm{Y} 1$ cells, and stable clones obtained after selection with geneticin were used in subsequent studies. Growth and morphology of mock- and DN-CK-II $\alpha$-transfected 3Y1 cells were similar under our cell culture conditions.

\section{RESULTS}

\section{cPGES is phosphorylated on serine residues in 3Y1 cells}

Figure 1(A) illustrates the potential phosphorylation sites (two consensus sites for PKC, three sites for CaMK-II, three sites for $\mathrm{CK}-\mathrm{II}$ and one site for tyrosine kinase) predicted from the primary amino acid sequence of human cPGES. In order to know whether or not cPGES undergoes phosphorylation in cells, rat fibroblastic $3 \mathrm{Y} 1$ cells, in which cPGES is the predominant PGES enzyme [18], were pre-incubated with $\mathrm{H}_{3}{ }^{32} \mathrm{PO}_{4}$, and cPGES protein was immunoprecipitated from the lysate of these cells, resolved by SDS/PAGE and subjected to autoradiography. As shown in Figure 1(B), there was a significant incorporation of radioactivity into cPGES protein even under basal culture conditions, and this phosphorylation was significantly increased in cells stimulated for 1 min with A23187. Phospho-amino acid analysis revealed that this phosphorylation occurred predominantly on serine, but not threonine and tyrosine, residues before and after A23187 stimulation (Figure 1C). Treatment of cell lysate with protein phosphatase decreased cPGES activity by $>90 \%$ (Figure 1D), suggesting that phosphorylation of cPGES is crucial for its enzymic function.

To corroborate the relationship between cPGES phosphorylation and its $\mathrm{PGE}_{2}$-biosynthetic function, we examined the effects of various protein kinase inhibitors on $\mathrm{PGE}_{2}$ production from exogenous AA by 3 Y 1 cells. As shown in Figure 1(E), conversion of exogenous AA into $\mathrm{PGE}_{2}$ by $3 \mathrm{Y} 1$ cells was markedly decreased by treatment with the CK-II inhibitor DRB or the tyrosine kinase inhibitor genistein, whereas the PKC inhibitor chelerythrine or the CaMK-II inhibitor KN-93 showed no inhibitory effects. However, since tyrosine phosphorylation of cPGES was undetectable (Figure 1C), the inhibitory effect of genistein observed here might have been a reflection of its indirect action (see below). As shown in Figure 1(F), genistein and DRB decreased cPGES phosphorylation significantly, whereas chelerythrine and KN-93 failed to do so, under these experimental conditions. The inability of chelerythrine and KN-93 to suppress $\mathrm{PGE}_{2}$ production and cPGES phosphorylation was not a result of their low concentrations, because they inhibited AA release from agonist-stimulated 3 Y 1 cells at the same concentrations (results not shown), in agreement with the potential role of PKC and CaMK-II in CPLA $_{2}$ activation $[23,24]$.

\section{cPGES is phosphorylated by CK-II in co-ordination with Hsp90 in vitro}

The above results suggest that CK-II is an attractive candidate for the protein kinase that phosphorylates and activates cPGES. To test this possibility, we examined with an in vitro kinase assay whether or not bacterial-derived recombinant cPGES is phosphorylated directly by CK-II. When recombinant cPGES was incubated for $30 \mathrm{~min}$ with an equivalent concentration of CK-II in the presence of $\mathrm{Mg}^{2+}$ and $\left[^{32} \mathrm{P}\right] \mathrm{ATP}$, there was a marked incorporation of ${ }^{32} \mathrm{P}$ into $\mathrm{CPGES}$ protein (Figure $2 \mathrm{~A}$, lower panel). Furthermore, the enzymic activity of cPGES was significantly increased following incubation with CK-II (Figure 2A, upper panel). Longer incubation of cPGES with CK-II did not result in further increases in the phosphorylation and activity of cPGES (results not shown), implying that cPGES maximally phosphorylated by CK-II alone exhibits approx. 3-fold higher activity than does the non-phosphorylated form in this experimental setting. When Hsp90, which is known to bind both cPGES [10] and CK-II $[19,20]$, was added to this in vitro kinase assay mixture, there were further increases in ${ }^{32} \mathrm{P}$ incorporation into cPGES protein and in 

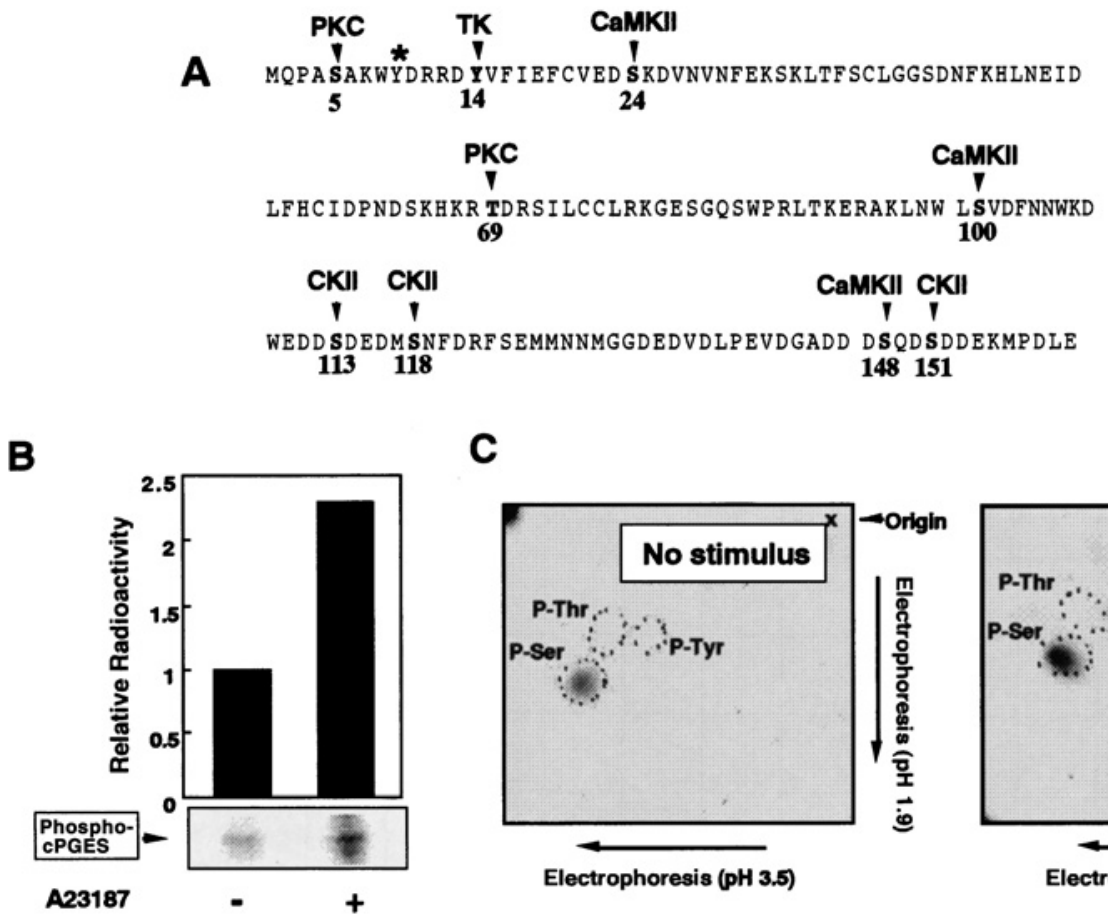

C

D

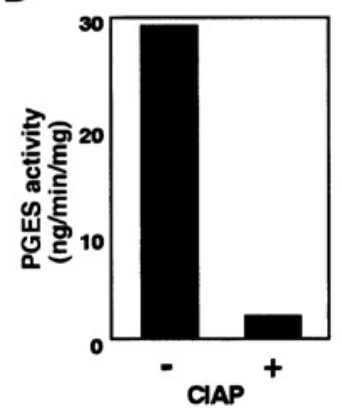

E

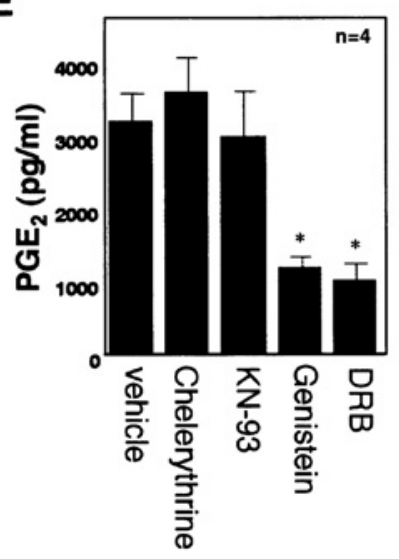

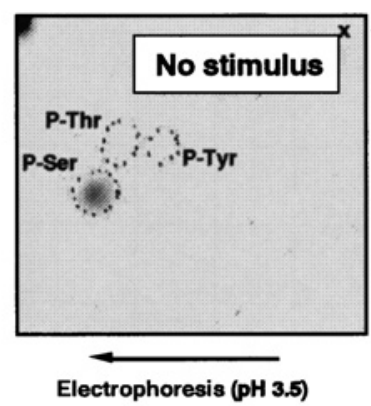

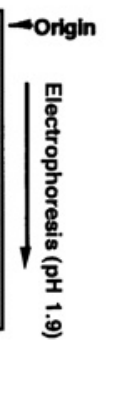

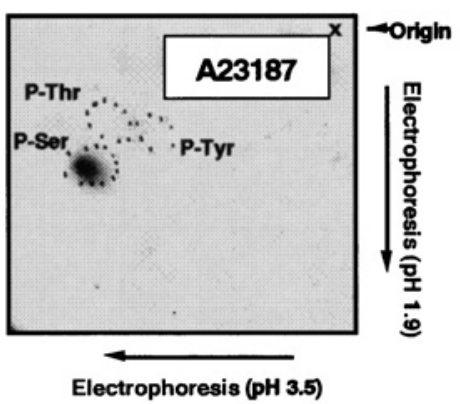

$\mathbf{F}$

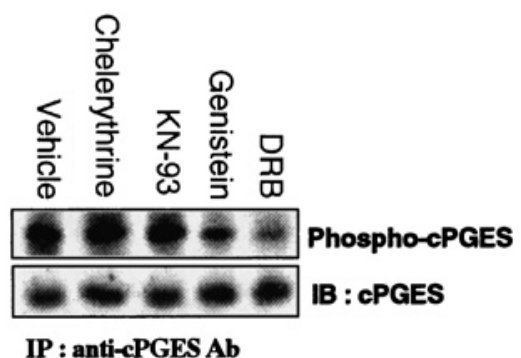

IP : anti-cPGES Ab

Figure 1 cPGES is phosphorylated on serine residues in $3 Y 1$ cells

(A) Putative phosphorylation sites on human cPGES predicted from its primary amino acid sequence. The asterisk indicates a tyrosine residue required for enzyme catalysis [10]. TK, tyrosine kinase. (B) ${ }^{32}$ P-pre-labelled 3Y1 cells were incubated for 1 min with or without A23187, and CPGES protein was immunoprecipitated from cell Iysates. Then the pellets were resolved on SDS/PAGE and subjected to autoradiography (lower panel). Relative incorporation of ${ }^{32} \mathrm{P}$ into cPGES protein was determined by scanning with a BAS image analyser (Fuji film) (upper panel). (C) Phospho-amino acid analysis. ${ }^{32}$ P-containing CPGES protein bands with or without A23187 stimulation were excised from the SDS/PAGE gel, digested, and separated by two-dimensional TLC. The positions of phosphoserine, phosphothreonine and phosphotyrosine residues are shown. (D) Effect of calf intestine alkaline phosphatase (CIAP) on cPGES activity in 3Y1 cells. After incubation of cell Iysate with $(+)$ or without $(-)$ CIAP for $2 \mathrm{~h}$ at $37^{\circ} \mathrm{C}$, PGES activity was measured. (E) Effects of various protein kinase inhibitors on PGE 2 production by $3 \mathrm{Y} 1 \mathrm{cells}$ after incubation for 30 min with $10 \mu \mathrm{M}$ AA. The cells were pre-treated with $10 \mu \mathrm{M}$ chelerythrine (PKC inhibitor), $0.4 \mu \mathrm{M} \mathrm{KN}-93$ (CaMK-II inhibitor), $100 \mu \mathrm{M}$ genistein (tyrosine kinase inhibitor), $100 \mu \mathrm{M}$ DRB (CK-II inhibitor) or vehicle (DMSO) for $5 \mathrm{~h}$. PGE released into the supernatants was quantified ( $n=4$; means + S.D.: ${ }^{\star} P<0.01$ compared with vehicle). (F) Effects of protein kinase inhibitors on cPGES phosphorylation. ${ }^{32} \mathrm{P}$-pre-labelled $3 \mathrm{Y} 1$ cells were pre-incubated for $5 \mathrm{~h}$ with the aforementioned protein kinase inhibitors, and incorporation of ${ }^{32} \mathrm{P}$ into $\mathrm{CPGES}$ was assessed by immunoprecipitation, followed by SDS/PAGE and autoradiography. Immunoblotting with anti-cPGES antibody was performed to confirm equal sample loading into each lane. IP, immunoprecipitation; IB, immunoblotting. Representative results of three independent experiments are shown in (B-D) and (F).

cPGES enzymic activity (Figure 2A). As shown in Figure 2(B), the maximal activation of cPGES was achieved when the three components (cPGES, CK-II and Hsp90) were mixed at a molar proportion of $1: 1: 1$. Thus it appears that Hsp90 modulates the conformation of cPGES, thereby allowing cPGES to be phosphorylated further by CK-II. There was no increase in cPGES activity when cPGES was incubated with CK-II (with or without Hsp90) in the absence of $\mathrm{ATP} / \mathrm{Mg}^{2+}$ (i.e. the conditions under which cPGES phosphorylation did not take place), and CK-II or Hsp90 by itself exhibited no PGES activity (results not shown).

When the mixture of cPGES and CK-II was immunoprecipitated with anti-cPGES antibody and then immunoblotted with anti-CK-II antibody, CK-II was co-precipitated with cPGES (see supplementary Figure 1A at http://www.BiochemJ.org/bj/380/ bj3810059add.htm). Conversely, cPGES was co-precipitated with 

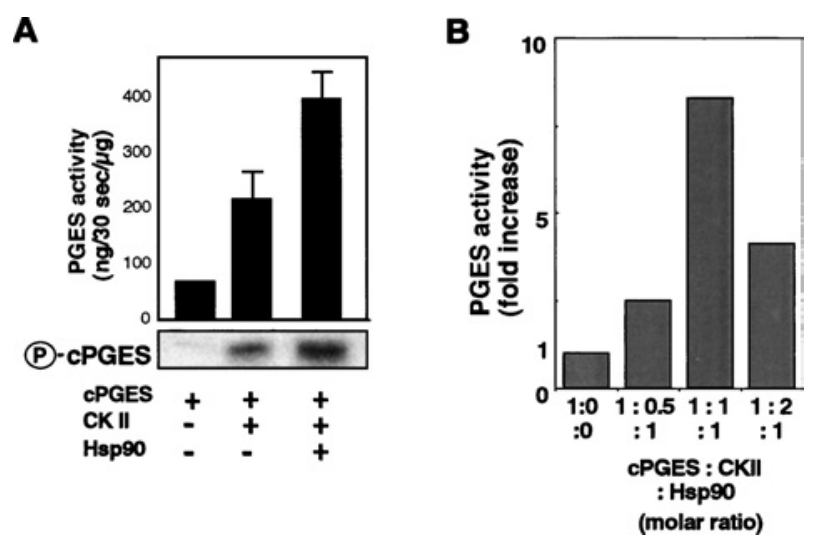

Figure 2 In vitro phosphorylation and activation of cPGES by CK-II and augmentation by Hsp90

(A) E. coli-derived recombinant cPGES $(3 \mu \mathrm{g})$ was incubated for $30 \mathrm{~min}$ at $30^{\circ} \mathrm{C}$ with recombinant CK-II with (+) or without (-) Hsp90 in the presence of $\mathrm{Mg}^{2+}$ and [ ${ }^{32}$ P]ATP. The molar proportion of CPGES, CK-II and Hsp90 was adjusted to 1:1:1. After brief boiling, samples were applied to SDS/PAGE followed by autoradiography (lower panel). Aliquots of samples were taken for PGES enzyme assay using $15 \mu \mathrm{M} \mathrm{PGH}_{2}$ as a substrate (upper panel). Values indicate fold-increases in PGES activity relative to that of CPGES alone ( $n=3$; means \pm S.D.). (B) Effects of various ratios of CPGES, CK-II and Hsp90 on CPGES activity.

CK-II from the mixture by anti-CK-II antibody. Thus there is direct physical interaction between cPGES and CK-II. When Hsp90 was added to this mixture, it was co-immunoprecipitated with cPGES and CK-II by anti-cPGES antibody, and more CK-II was associated with cPGES in the presence of Hsp90 than in its absence (supplementary Figure 1A). Hsp90 was also coprecipitated when the pull-down assay was conducted with antiCK-II antibody. These results suggest that the formation of the tertiary complex comprising cPGES, CK-II and Hsp90 facilitates the CK-II-directed phosphorylation of cPGES. Furthermore, when the mixture of cPGES, CK-II and Hsp90 was incubated with the CK-II inhibitor DRB, cPGES phosphorylation and its binding to CK-II were completely lost (see supplementary Figure $1 \mathrm{~B}$ at http://www.BiochemJ.org/bj/380/bj3810059add.htm), indicating that the phosphorylation of cPGES by CK-II is essential for their subsequent association. Under this condition, cPGES enzymic activity was decreased to the basal level by DRB (results not shown). In addition, the amount of Hsp90 co-precipitated with cPGES was decreased by half in the presence of DRB (supplementary Figure 1B), suggesting that, although cPGES and Hsp90 can bind even without CK-II, the binding of Hsp90 to cPGES increases when cPGES is phosphorylated by CK-II.

Kinetic analysis (see supplementary Figure 2 at http://www. BiochemJ.org/bj/380/bj3810059add.htm) revealed that the $K_{\mathrm{m}}$ values of cPGES alone, cPGES plus CK-II, and cPGES and CK-II plus $\mathrm{Hsp} 90$ for $\mathrm{PGH}_{2}$ were estimated to be $66.6,35.7$ and $14.9 \mu \mathrm{M}$ and the $V_{\max }$ values to be 2.0,2.2 and $2.5 \mu \mathrm{mol} / \mathrm{min}$ per mg of protein respectively. Thus the phosphorylation of cPGES with CK-II results in a decrease of its $K_{\mathrm{m}}$ and only a modest increase in its $V_{\max }$, and these changes are facilitated when Hsp90 is added. Of note, the $K_{\mathrm{m}}$ and $V_{\max }$ values of cPGES combined with CK-II and Hsp90 are similar to those of purified recombinant mPGES-2 [9].

\section{cPGES-CK-II-Hsp90 tertiary complex formation is critical for cPGES activation in agonist-stimulated $3 Y 1$ cells}

We then asked if cPGES-CK-II-Hsp90 complex formation, with its attendant phosphorylation, is crucial for the $\mathrm{PGE}_{2}$-biosynthetic function of cPGES in vivo. Stimulation of 3Y1 cells with A23187 for $5 \mathrm{~min}$ resulted in increased phosphorylation of cPGES (Figure $3 \mathrm{~A}$, top panel), which was accompanied by marked increases in cellular $\mathrm{PGE}_{2}$ production (Figure $3 \mathrm{~A}$, middle panel) and cPGES enzymic activity in cell lysates (Figure 3A, bottom panel). These three events were reversed to their basal levels in cells treated with DRB or genistein (Figure 3A). Co-immunoprecipitation experiments using anti-cPGES antibody revealed that cPGES was complexed with CK-II and Hsp90 in cells even under basal culture conditions, and that their association was significantly elevated as early as 1 min after A23187 stimulation (Figure 3C), correlating with kinetic increases in $\mathrm{PGE}_{2}$ production and cPGES activity (Figure 3B). The increased association of these three components persisted for up to $30 \mathrm{~min}$ (results not shown), a period during which $\mathrm{PGE}_{2}$ production continued to increase [18]. Treatment of the cells with DRB (Figure 3D) or genistein (results not shown) resulted in marked reduction of cPGES association with CK-II and Hsp90 under basal and A23187-stimulated conditions. Furthermore, treatment of the cells with geldanamycin, an Hsp90 inhibitor, also reversed stimulus-coupled association of cPGES with CK-II and Hsp90 (Figure 3E).

To assess if similar events occurred following a physiological stimulus, we next stimulated 3 Y1 cells with bradykinin. Addition of $10 \mu \mathrm{M}$ bradykinin to cells elicited immediate $\mathrm{PGE}_{2}$ production, which increased markedly during the initial $3 \mathrm{~min}$ and then reached a plateau (Figure 4A). This prompt response was abrogated by the bradykinin receptor B2 antagonist HOE140 (results not shown), verifying the G-protein-coupled receptor-mediated process. Immunoprecipitation of cPGES from replicate ${ }^{32} \mathrm{P}$-prelabelled cells revealed that phosphorylation of cPGES was markedly increased at $1 \mathrm{~min}$ and then declined to the basal state by 5-10 min (Figure 4A, upper panel), revealing that cPGES phosphorylation shows correlation with ongoing $\mathrm{PGE}_{2}$ synthesis. In accordance with cPGES phosphorylation, cPGES enzymic activity in cell lysates was increased markedly at $1 \mathrm{~min}$ after bradykinin stimulation and declined at $10 \mathrm{~min}$ (Figure 4B). Association of CK-II with cPGES, as assessed by the immunoprecipitation assay, was also markedly elevated at $1 \mathrm{~min}$ and then returned to the basal level (Figure 4B, upper panel). Furthermore, increased association of cPGES with Hsp90 was transient, peaking at $1 \mathrm{~min}$ and returning to the basal level by $10 \mathrm{~min}$ (Figure $4 \mathrm{~B}$, upper panel). It is notable that the PGES activity at the 10-min point tended to retain elevated activity (even if statistically insignificant) without elevated phosphorylation over the basal level. This might reflect the existence of an additional regulatory mechanism for cPGES activity, which is beyond the scope of the present study.

As in the case of the A23187-evoked response, bradykininstimulated $\mathrm{PGE}_{2}$ production and cPGES activity were markedly suppressed by DRB or geldanamycin (Figure 4C). Moreover, DRB or geldanamaycin prevented the bradykinin-induced association of cPGES with CK-II and Hsp90 (Figure 4D). Neither DRB nor geldanamycin affected AA release from A23187- or bradykinin-stimulated $3 \mathrm{Y} 1$ cells (results not shown), indicating that these agents did not affect the activation of $\mathrm{CPLA}_{2}$, an upstream event of stimulus-coupled $\mathrm{PGE}_{2}$ production.

\section{DN-CKII attenuates cPGES activation in 3Y1 cells}

To gain further insight into the contribution of CK-II to cPGES activation, we took advantage of DN-CK-II, which harbours a mutation in the kinase domain and thereby blocks the cellular functions of CK-II [22]. To this end, DN-CK-II was transfected 
A
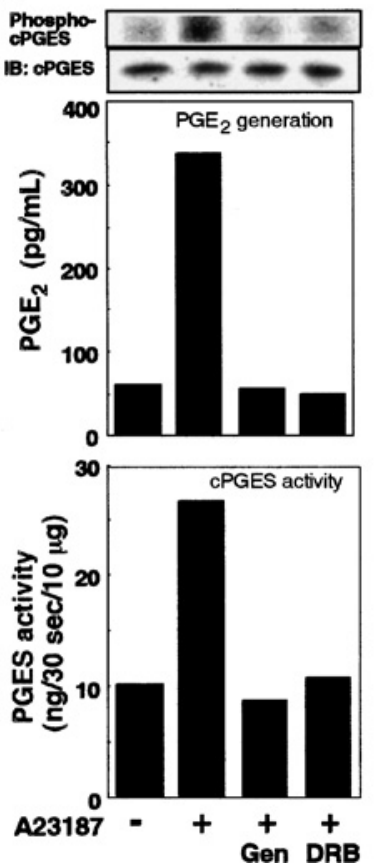

B
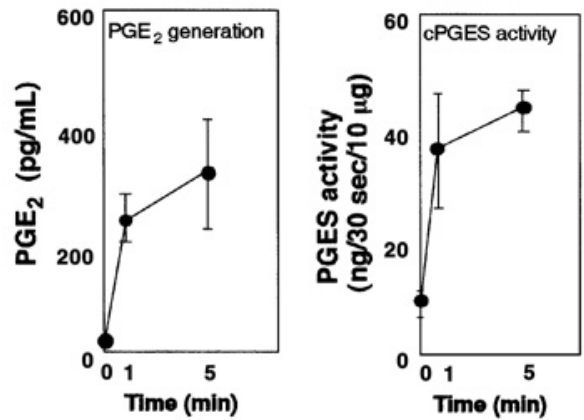

C

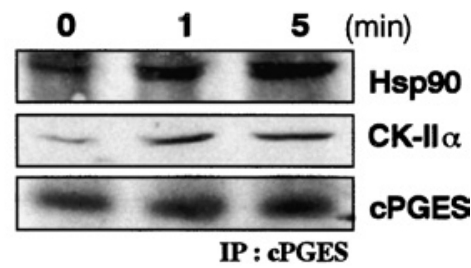

D

DRB

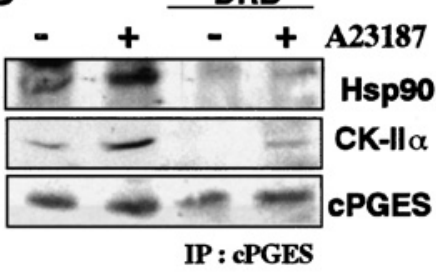

E

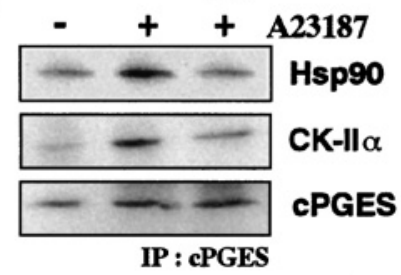

Figure 3 A23187-induced phosphorylation and activation of cPGES

(A) $3 \mathrm{Y} 1$ cells pre-treated for $5 \mathrm{~h}$ with or without $100 \mu \mathrm{M}$ genistein (Gen) or $100 \mu \mathrm{M}$ DRB were stimulated with (+) or without (-) $10 \mu \mathrm{M} \mathrm{A23187} \mathrm{for} 1$ min, and PGE 2 production (middle panel) and cPGES enzymic activity (bottom panel) were assessed. Lysates of replicate 32P-pre-labelled cells were subjected to immunoprecipitation with anti-cPGES antibody, followed by SDS/PAGE and autoradiography to detect phosphorylated CPGES (top panel). Equal precipitation of CPGES protein from each sample was verified by immunoblotting. (B) Time course of PGE 2 generation (left-hand panel) and cPGES enzymic activity (right-hand panel) after A23187 stimulation ( $n=4$; means \pm S.D.). (C) A23187-induced formation of the cPGES-CK-II-Hsp90 complex. Cells were stimulated for the indicated periods with A23187, lysed, and subjected to immunoprecipitation (IP) with anti-cPGES antibody. The pellets were resolved by SDS/PAGE, followed by immunoblotting with antiHsp90, anti-CK-Il $\alpha$ and anti-cPGES antibodies. Effects of $100 \mu \mathrm{M}$ DRB (D) or $1 \mu \mathrm{M}$ geldanamycin (GA) (E) on cPGES-CK-II-Hsp90 complex formation. Cells were pre-treated with these compounds for $5 \mathrm{~h}$ and then activated for $1 \mathrm{~min}$ with A23187. Cell lysates were taken for immunoprecipitation (IP) with anti-CPGES antibody, followed by SDS/PAGE and immunoblotting with anti-Hsp90, anti-CK-Il $\alpha$ and anti-cPGES antibodies. Representative results of three or four independent experiments are shown in $(\mathbf{A})$ and $(\mathbf{C}-\mathbf{E})$.

A

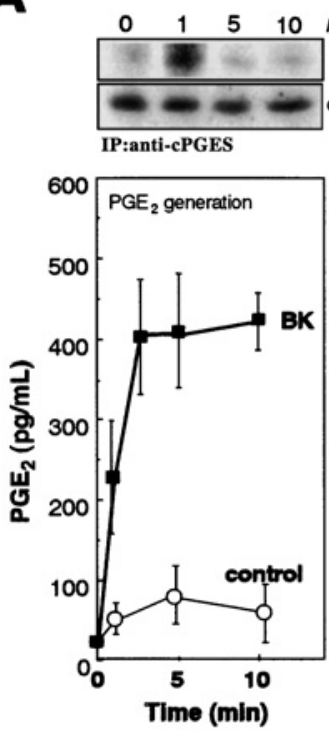

B
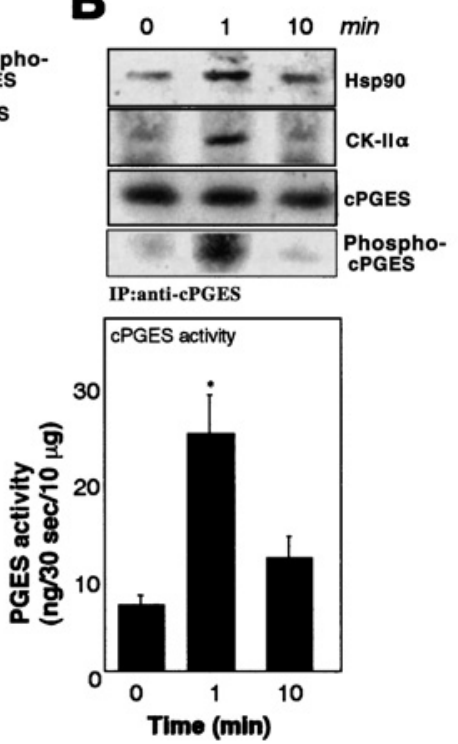
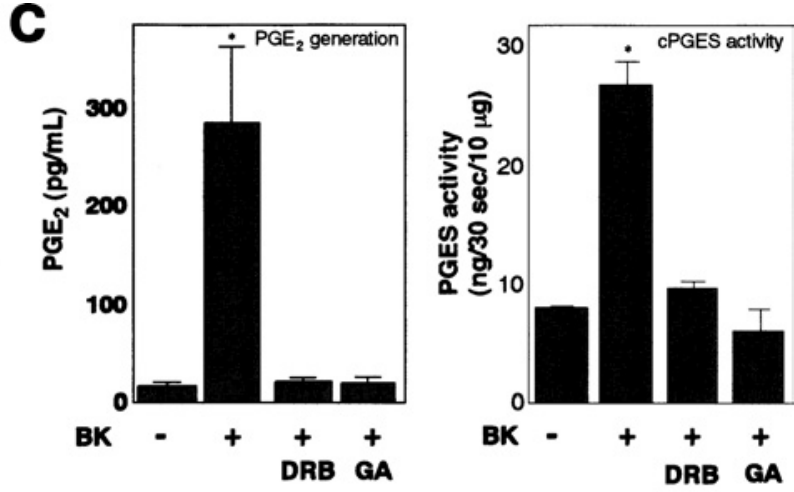

D

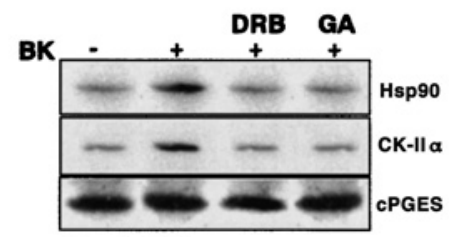

IP:anti-cPGES

Figure 4 Bradykinin (BK)-induced phosphorylation and activation of cPGES

(A) Time course of $\mathrm{PGE}_{2}$ production after incubation for the indicated periods with or without $10 \mu \mathrm{M} \mathrm{BK}$ (lower panel). Results are means \pm S.D. for four independent experiments. ${ }^{32} \mathrm{P}$-incorporation into CPGES (Phospho-cPGES) at each time point was assessed by immunoprecipitation and subsequent autoradiography, and equal precipitation of cPGES protein from each sample was verified by immunoblotting (upper panel). (B) Formation of the cPGES-CK-II-Hsp90 complex and cPGES phosphorylation after stimulation with BK for indicated periods were assessed by the immunoprecipitation (IP) assay (upper panel). PGES activity in cell lysates at each time point was measured (lower panel). Results are means + S.D. for seven independent experiments ${ }^{\star} P<0.05$ compared with experiments without BK stimulation). (C) Effects of DRB and geldanamycin (GA) on PGE 2 production (left-hand panel) and cPGES enzymic activity in cell lysates (right-hand panel). Cells were pre-incubated for $5 \mathrm{~h}$ with these agents and then treated for 1 min with $(+)$ or without $(-)$ BK. Results are means + S.D. for four independent experiments $\left({ }^{\star} P<0.05\right.$ compared with BK stimulation without inhibitors). (D) Effects of DRB and GA on the formation of the cPGES-CK-II-Hsp90 complex, as determined by immunoprecipitation and subsequent immunoblotting. A blot representative of five independent experiments is shown. 
A

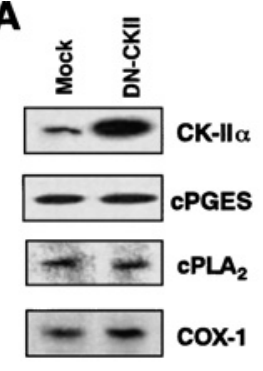

D

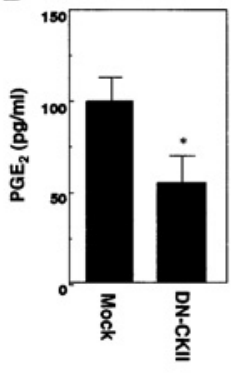

B

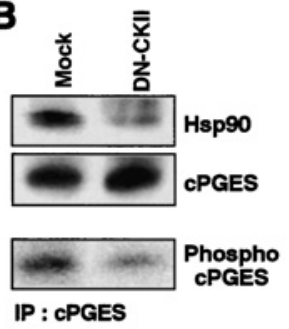

$\mathbf{E}$

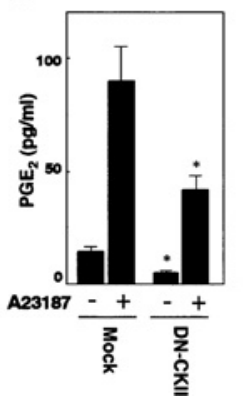

C

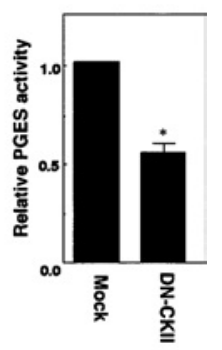

$\mathbf{F}$

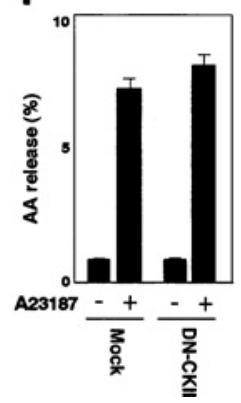

Figure 5 Effects of DN-CK-II on cPGES phosphorylation and function

(A) Expression levels of $\mathrm{PGE}_{2}$-biosynthetic enzymes in mock- or DN-CK-II-transfected 3Y1 cells, as assessed by immunoblotting. (B) Association of cPGES with Hsp90 (top panel) and phosphorylation of cPGES (middle panel) in mock- or DN-CK-II-transfected cells. CPGESHsp90 association was assessed by immunoprecipitation (IP) and subsequent SDS/PAGE and immunoblotting, and CPGES phosphorylation was assessed by immunoprecipitation from replicate ${ }^{32}$ P-labelled cells, followed by SDS/PAGE and autoradiography. Equal sample loading into each lane was verified by immunoblotting with anti-cPGES antibody (bottom panel). Blots representative of three independent experiments are shown. (C) CPGES enzymic activity in lysates of mock- or DN-CK-II-transfected cells. Values show relative enzymic activity, with the activity of control cells regarded as 1. (D) PGE 2 production by mock- or DN-CK-II-transfected cells treated for 30 min with $10 \mu \mathrm{M}$ AA. (E) PGE 2 production by A23187-stimulated mockor DN-CK-II-transfected cells. Cells were treated with (+) or without (-) $10 \mu \mathrm{M}$ A23187 for $30 \mathrm{~min}$. (F) AA release from mock- or DN-CK-II-transfected $3 \mathrm{Y} 1$ cells. Cells were pre-incubated with $\left[{ }^{3} \mathrm{H}\right] \mathrm{AA}$, and $\left[{ }^{3} \mathrm{H}\right] \mathrm{AA}$ release with $(+)$ or without (-) stimulation with $\mathrm{A} 23187$ for $30 \mathrm{~min}$ was measured. In $(\mathbf{C}-\mathbf{F})$, results are means \pm S.D. of three to five independent experiments $\left({ }^{\star} P<0.05\right.$ compared with replicate mock-transfected cells).

in $3 \mathrm{Y} 1$ cells, and cPGES phosphorylation, cPGES binding to Hsp90, cPGES enzymic activity and $\mathrm{PGE}_{2}$ generation in the transfectants were compared with those of mock-transfected cells. As assessed by Western blotting, the expression levels of the enzymes involved in the immediate $\mathrm{PGE}_{2}$-biosynthetic pathway, including $\mathrm{cPLA}_{2}$, COX-1 and cPGES, were comparable between mock- and DN-CK-II-transfected 3 Y1 cells (Figure 5A). In DNCK-II-transfected cells, the phosphorylation state of cPGES and the amount of Hsp90 co-immunoprecipitated with cPGES were decreased significantly relative to those in mock-transfected cells (Figure 5B). Accordingly, cPGES enzymic activity in the lysate of DN-CK-II-transfected cells was about half of that in the lysate of mock-transfected cells (Figure 5C). Moreover, $\mathrm{PGE}_{2}$ generation by DN-CK-II-transfected cells from exogenous AA (Figure 5D) or from endogenous AA in response to A23187 (Figure 5E) was also reduced by half as compared with that by replicate control cells. In contrast, the A23187-stimulated AA-releasing responses in DN-CK-II- and mock-transfected cells were similar (Figure $5 \mathrm{~F}$ ), indicating that $\mathrm{CPLA}_{2}$ activation was unaffected by DNCK-II. These results, together with studies using various inhibitors (Figures 3 and 4), imply that complex formation of cPGES with CK-II and Hsp90, and attendant phosphorylation by CK-II are essential for the activation of cPGES in cells.

\section{Mutation studies}

There are three Ser-Xaa-Xaa acidic consensus motifs for CKII phosphorylation $[25,26]$ in cPGES $\left(\operatorname{Ser}^{113}, \operatorname{Ser}^{118}\right.$ and $\operatorname{Ser}^{151}$ ) (Figure 1). To address which residues are involved in CK-IIdirected cPGES phosphorylation, we constructed cPGES point mutants in which each serine residue was replaced with alanine or glycine (S113A, S118A and S151G), as illustrated in Figure 6(A). Since genistein blocks cPGES phosphorylation and function (Figures 1 and 3), we also made a Y14F mutant in which the only potential tyrosine kinase phosphorylation site $\mathrm{Tyr}^{14}$ was replaced with phenylalanine. These mutants were transfected into $3 \mathrm{Y} 1$ cells, and their enzymic activities and $\mathrm{PGE}_{2}$-biosynthetic functions were compared with those of WT (wild-type) enzyme. The expression levels of WT and mutant enzymes, as assessed by Western blotting with anti-FLAG antibody, were similar (although the expression level of S118A was slightly higher than others) (Figure 6B), which allowed direct comparison of their $\mathrm{PGE}_{2}-$ producing capacities.

cPGES enzymic activity was increased significantly in cells transfected with WT, S151G or Y14F, whereas the activity in cells transfected with S113A or S118A was comparable with that in parental cells (Figure 6C). Likewise, cellular $\mathrm{PGE}_{2}$ production from exogenous AA was elevated significantly when WT, S151G or Y14F was transfected, whereas that by cells transfected with S113A or S118A was not appreciably increased over that by parental cells (Figure 6D). Furthermore, A23187- (Figure 6E) or bradykinin- (Figure 6F) stimulated $\mathrm{PGE}_{2}$ production, which was increased markedly in WT-, S151G- or Y14F-transfected cells, was similar between parental cells and S113A- or S118A-transfected cells. Although A23187-induced $\mathrm{PGE}_{2}$ production by S151G-transfected cells appeared slightly lower than that by WTtransfected cells (Figure 6E), this difference was not statistically significant. To assess whether or not these mutant enzymes could be phosphorylated in cells, the WT and mutant cPGES proteins were immunoprecipitated from ${ }^{32} \mathrm{P}$-pre-labelled cells with antiFLAG antibody and were subjected to SDS/PAGE followed by autoradiography. As shown in Figure 6(G), incorporation of ${ }^{32} \mathrm{P}$ into FLAG-tagged cPGES was observed in WT-, Y14F- or S151Gtransfected cells, whereas that in S113A- or S118A-transfected cells was minimal.

To unveil further that $\operatorname{Ser}^{113}$ and $\operatorname{Ser}^{118}$ are essential for cPGES to interact with CK-II, equal amounts of recombinant WT cPGES and three point mutants (S113A, S118A and S151G) were each incubated with CK-II in vitro. As shown in Figure 6(H), the enzymic activities of WT and S151G were elevated to a similar extent after incubation with CK-II, whereas S113A or S118A, which exhibited a basal activity comparable with that of the WT enzyme, failed to be activated by CK-II. Under this condition, WT, but not S113A and S118A, bound to CK-II, as revealed by the immunoprecipitation assay (Figure 6I). Furthermore, when Hsp90 was added to the incubation mixture, less Hsp90 was complexed with S113A and S118A than with the WT enzyme (Figure 6I). In contrast, association of S151G with CK-II and Hsp90 was similar to that of WT.

Based on these observations, we conclude that $\operatorname{Ser}^{113}$ and $\mathrm{Ser}^{118}$ are the predominant CK-II phosphorylation sites critical for cPGES activation, and that phosphorylation of these two serine residues by CK-II facilitates cPGES association with Hsp90, even though the basal cPGES-Hsp90 association can occur without this phosphorylation event. In addition, the lack of appreciable effect of the $\mathrm{Tyr}^{14}$ mutation (Figure 6) supports the notion that cPGES activation depends essentially on serine phosphorylation by CK-II and that the inhibitory effect of genistein observed above may be due to its indirect inhibition of upstream signalling events leading to $\mathrm{CK}$-II activation. 


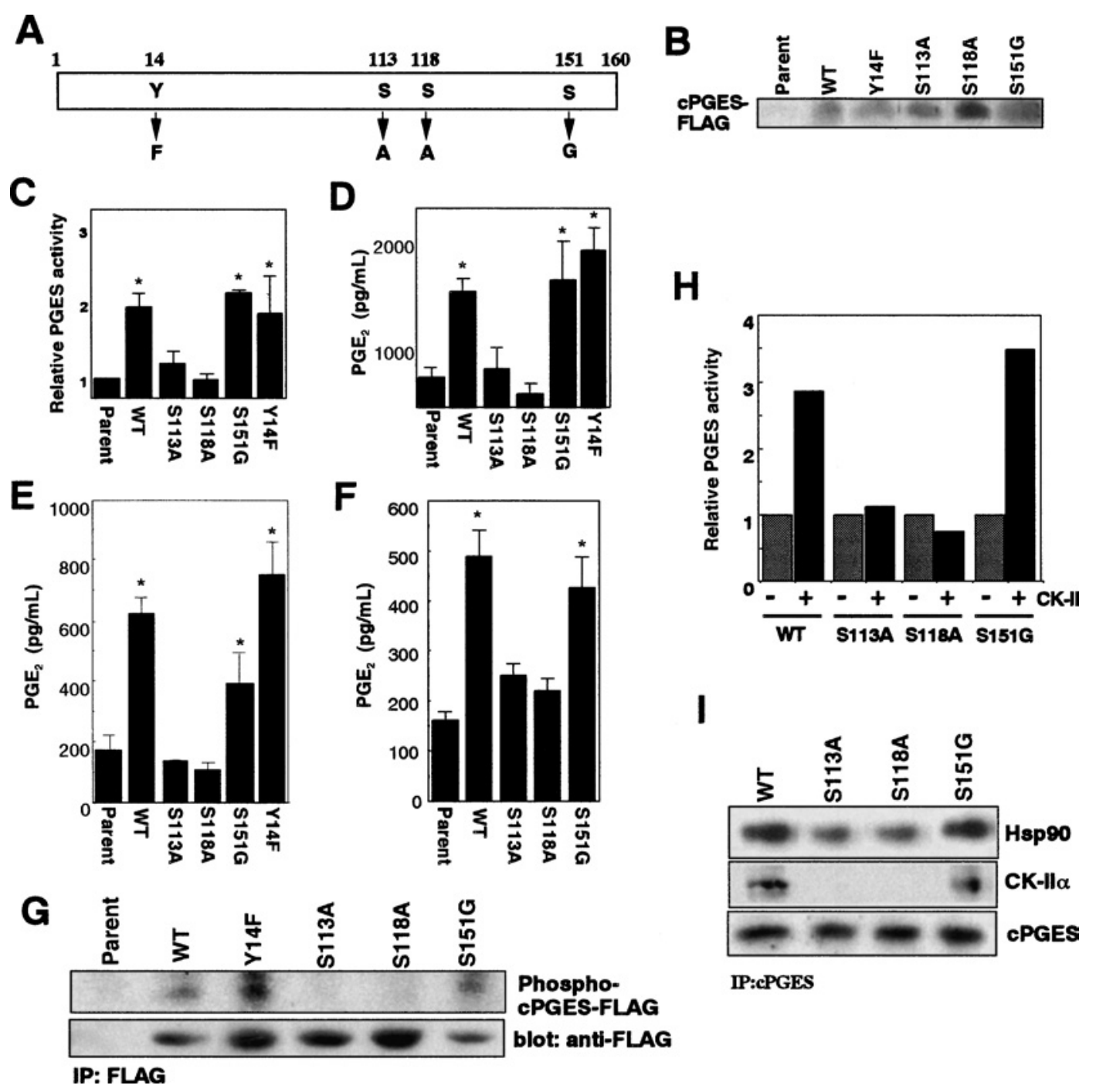

Figure 6 Determination of CK-II phosphorylation sites by using cPGES mutants

(A) Schematic structure of CPGES mutants. (B) Expression of FLAG-tagged WT and mutant CPGES proteins in 3 Y1 transfectants, as assessed by immunoblotting with anti-FLAG antibody. Equal numbers of cells ( $10^{5}$ equivalents) were applied to individual lanes. (C) CPGES enzymic activity in lysates of the transfectants. Values show relative enzymic activity, with that of parental cells regarded as 1. (D-F) PGE production by the transfectants and parental cells after treatment for 30 min with $10 \mu \mathrm{M} \mathrm{AA}(\mathbf{D}), 10 \mu \mathrm{M}$ A23187 (E), and $10 \mu \mathrm{M}$ bradykinin (F). Results are means + S.D. for three to five independent experiments $\left({ }^{\star} P<0.05\right.$ compared with replicate parental cells). (G) Phosphorylation of WT and mutant cPGES proteins. Cells pre-labelled with ${ }^{32} P$ were lysed and were subjected to immunoprecipitation (IP) with anti-FLAG antibody. Individual samples were resolved by SDS/PAGE and were subjected to autoradiography to detect phosphorylated cPGES or to immunoblotting with anti-FLAG antibody to verify appropriate precipitation of FLAG-tagged proteins from individual samples. (H) Recombinant WT and mutant cPGES proteins were incubated with (+) or without (-) CK-II, and their PGES activities were measured. Result indicates relative PGES activity regarding the activity of WT enzyme without incubation with CK-II as 1. (I) The mixture of cPGES (either WT or mutants), CK-II and Hsp90 was immunoprecipitated with anti-cPGES antibody, applied to SDS/PAGE, and subjected to immunoblotting with respective antibodies.

\section{Modulation of cPGES activation by p38 MAPK}

Since activation of CK-II occurs downstream of p38 MAPK [27,28], we next assessed the effect of SB20358, a p38 inhibitor, on cPGES activation. Treatment of 3Y1 cells with SB20358 resulted in marked reduction of $\mathrm{PGE}_{2}$ generation induced by A23187 (results not shown) or bradykinin (Figure 7A). The stimulus-coupled increase in cPGES enzymic activity was also markedly suppressed by SB20358 (Figure 7B), even though there is no MAPK consensus phosphorylation site on the cPGES molecule. Importantly, SB20358 potently blocked the association of cPGES with CK-II and Hsp90, as well as cPGES phosphorylation (Figure 7C). These results suggest that the inhibition of the p38 pathway results in attenuation of the cPGES activation machinery, probably through perturbing the signal transduction leading to CK-II activation.

\section{Glucocorticoid attenuates cPGES activation}

When $3 \mathrm{Y} 1$ cells were treated with the anti-inflammatory glucocorticoid dexamethasone, A23187-induced $\mathrm{PGE}_{2}$ generation (Figure 8A) and cPGES activity in cell lysates (results not shown) were significantly reduced. In contrast, AA release was not affected significantly by dexamethasone (Figure $8 \mathrm{~B}$ ), indicating that $\mathrm{cPLA}_{2}$, an initiator of AA metabolism [1], is not a primary target for the action of dexamethasone. Strikingly, A23187-stimulated association of cPGES with Hsp90 (Figure 8C) and 

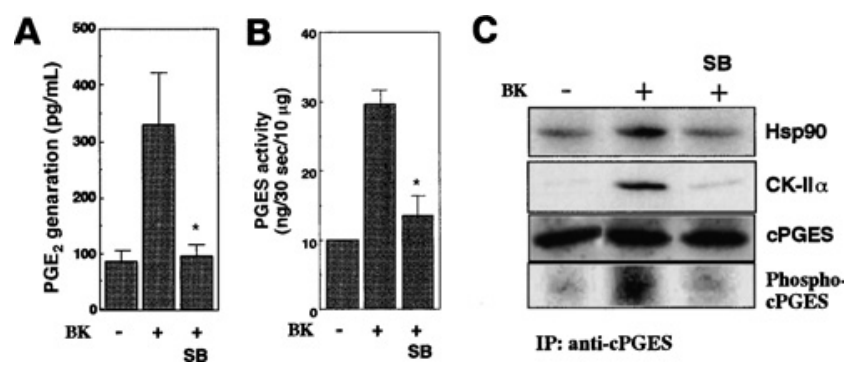

Figure 7 Effect of p38 MAPK inhibitor on cPGES activation

(A and B) 3 Y1 cells were treated for 2 min with (+) or without (-) bradykinin (BK) in the presence or absence of the p38 inhibitor SB20358 (SB), and PGE 2 released into the supernatants $(\mathbf{A})$ and PGES enzymic activity in cell lysates (B) were measured. Results are means \pm S.D. for three independent experiments ( ${ }^{\star} P<0.05$ compared with BK stimulation in the absence of $\mathrm{SB}$ ). (C) Cell lysates were subjected to immunoprecipitation with anti-cPGES antibody, followed by SDS/PAGE and immunoblotting with antibodies for Hsp90, CK- $\|_{\alpha}$ and cPGES. Replicate immunoprecipitates from ${ }^{32} \mathrm{P}$-pre-labelled cells were subjected to immunoprecipitation (IP), SDS/PAGE, and then autoradiography to detect a phosphorylated form of CPGES. Blots are representative of three experiments.
A

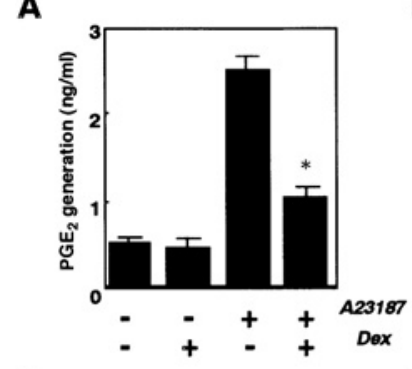

C

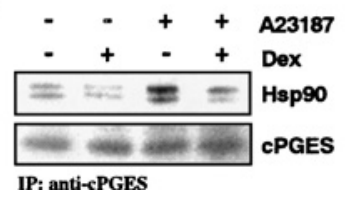

B

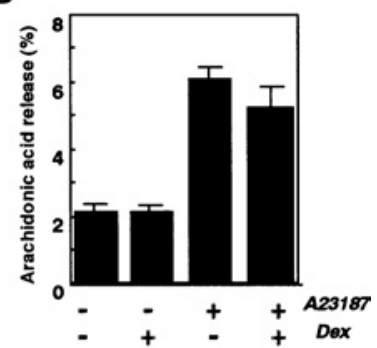

D

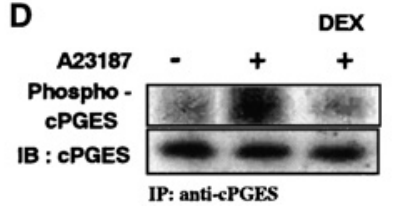

Figure 8 Effect of dexamethasone (Dex) on cPGES activation

(A and B) $3 Y 1$ cells were treated for 10 min with (+) or without (-) A23187 in the presence $(+)$ or absence $(-)$ of $1 \mu \mathrm{M} \mathrm{Dex}$, and $\mathrm{PGE}_{2}(\mathbf{A})$ and $\mathrm{AA}(\mathbf{B})$ released into the supernatants were measured. Results are means \pm S.D. for three independent experiments. (C) Cell lysates were subjected to immunoprecipitation (IP) with anti-cPGES antibody, followed by immunoblotting with antibodies against Hsp90 and cPGES. (D) Replicate lysates of ${ }^{32} \mathrm{P}$-pre-labelled cells were subjected to immunoprecipitation with anti-cPGES antibody, followed by SDS/PAGE and autoradiography or immunoblotting with anti-cPGES antibody. Blots in (C) and (D) are representative of three independent experiments.

phosphorylation of cPGES (Figure 8D) were significantly reduced in dexamethasone-treated cells as compared with those in replicate dexamethasone-untreated cells. Thus it appears that the blockage of immediate $\mathrm{PGE}_{2}$ generation by dexamethasone is due to inhibition of the cPGES-activation machinery, consistent with the fact that the activation of $\mathrm{p} 38$, an upstream regulator of CK-II (see above), is suppressed by glucocorticoids [29-31].

\section{DISCUSSION}

In the present study, we have provided evidence that the cellular $\mathrm{PGE}_{2}$-biosynthetic function of cPGES in activated cells is profoundly controlled by CK-II-promoted phosphorylation. The following observations support this interpretation. First, cPGES was directly phosphorylated by CK-II in vitro, which was accompanied by increase in its enzymic activity. Based on the kinetic studies, this CK-II effect is ascribed mainly to increased affinity of cPGES for the substrate $\mathrm{PGH}_{2}$. Secondly, cPGES phosphorylation occurred in cells, and this event was markedly suppressed by DRB, a CK-II inhibitor. This accorded with blockage of cellular $\mathrm{PGE}_{2}$ production from exogenous and endogenous AA and of stimulus-increased cPGES enzymic activity. Thirdly, increased cPGES phosphorylation after cell activation occurred in parallel with ongoing $\mathrm{PGE}_{2}$ production and its increased association with CK-II. Fourthly, overexpression of DN-CK-II resulted in concomitant reduction in cPGES phosphorylation, cPGES enzymic activity and $\mathrm{PGE}_{2}$ generation. Fifthly, cPGES mutants with alterations in either $\operatorname{Ser}^{113}$ or $\operatorname{Ser}^{118}$, two of the three predicted CK-II phosphorylation sites in cPGES, failed to be phosphorylated and activated both in vitro and in vivo. Collectively, these results suggest that the temporary phosphorylation of both of these serine residues by CK-II is crucial for optimal activation of cPGES in cells. Finally, a p38 MAPK inhibitor and dexamethasone indirectly suppressed cPGES activation, most likely at the CK-II-mediated phosphorylation step.

Regulation of eicosanoid generation by phosphorylation of biosynthetic enzymes by particular kinases has been demonstrated in several studies [23,24,32-35]. It is well known that activation of $\mathrm{cPLA}_{2}$ is regulated by direct phosphorylation by MAPKs [23,32], MAPK-activated protein kinases [33] and CaMK-II [24]. 5-Lipoxygenase, a rate-limiting enzyme for leukotriene biosynthesis, also undergoes phosphorylation by MAPKs [34] and MAPK-activated protein kinase 2 [35], a process possibly leading to optimal activation of 5-lipoxygenase at low intracellular $\mathrm{Ca}^{2+}$ levels. MAPKs also play a role in stimulus-coupled transcriptional activation of the $C O X-2$ and $m P G E S-1$ genes in several situations [15,36-38]. However, there has been no convincing evidence that the functions of terminal eicosanoid synthases are regulated by direct phosphorylation and that CK-II can participate in the regulation of eicosanoid biosynthesis. Thus our present finding that cPGES activation is controlled by temporary phosphorylation by CK-II has opened a new insight into the eicosanoid field. Even though the enzymic activity of cPGES in vitro or in cell lysates is increased only several-fold by CK-II-directed phosphorylation, its cellular $\mathrm{PGE}_{2}$-biosynthetic function is profoundly affected by this phosphorylation event. This situation is similar to the MAPKdependent regulation of $\mathrm{cPLA}_{2}$; phosphorylation of $\mathrm{cPLA}_{2}$ by MAPKs results only in a 2-3-fold increase in its enzymic activity in vitro or in cell lysates, but this event is essential for its cellular AA-releasing function [23,32].

cPGES was originally characterized as the Hsp90 co-chaperone p23, modifying the molecular chaperone function of Hsp90 [39-42]. After our initial discovery of the PGES activity of p23 [10], we recently reported that this particular enzymic function is facilitated by its interaction with Hsp90 [18]. In the present study, we have provided further support for the notion that Hsp90 plays a critical role in the regulation of cPGES function probably through facilitating the interaction between cPGES and CK-II. In vitro reconstitution experiments revealed that formation of the cPGES-CK-II-Hsp90 complex increased cPGES enzymic activity further by decreasing its $K_{\mathrm{m}}$ value for $\mathrm{PGH}_{2}$. Considering the limited availability of $\mathrm{PGH}_{2}$ in the intracellular microenvironment, this $K_{\mathrm{m}}$ shift may be crucial for the enzyme to become active in cells. Indeed, cell activation led to a transient increase in the formation of this tertiary complex, at which time increased cPGES phosphorylation and $\mathrm{PGE}_{2}$ generation occurred in parallel. Moreover, treatment of cells with the Hsp90 inhibitor geldanamycin resulted in disruption of the tertiary complex, eventually preventing cPGES from being phosphorylated and thereby activated by CK-II. Thus cPGES cannot properly function 
as PGES in cells unless it is complexed with (and thus phosphorylated by) CK-II with the aid of Hsp90. It is known that CK-II binds to the middle domain, whereas cPGES binds to the $\mathrm{N}$-terminal ATPase domain, of an Hsp90 molecule [43]. Conceivably, Hsp90 may act as an essential scaffold protein that brings cPGES and CK-II in proximity, thereby spatially allowing their efficient functional interaction under physiological conditions. In addition, conformational changes in cPGES and CK-II by Hsp90 in the same complex $[19,20]$ may also influence their interaction and activation.

CK-II, a ubiquitous serine/threonine protein kinase composed of two $\alpha$ and two $\beta$ subunits, plays crucial roles in diverse cellular signalling events leading to growth, survival, differentiation and apoptosis [44-51]. For instance, CK-II modulates the functions of $\mathrm{p} 53$ in the stress response [45-47], NF- $\kappa \mathrm{B}$ (nuclear factor $\kappa \mathrm{B}$ ) following pro-inflammatory stimuli $[28,48,49], \beta$-catenin in the Wnt signalling pathway [50] and Bid during apoptosis [51]. Upstream events leading to CK-II activation following cell activation involve the p38 MAPK pathway [27,28]. In fact, our results using a p38 inhibitor suggest that the p38 pathway places upstream of CK-II. Thus suppression of CK-II activation, and therefore cPGES activation, by the tyrosine kinase inhibitor genistein is likely to be due to perturbation of the p38 pathway, in which tyrosine phosphorylation events could be involved. Moreover, CK-II activation occurs following $\mathrm{Ca}^{2+}$ signalling in concert with certain tyrosine kinases [52], consistent with our present findings that $\mathrm{Ca}^{2+}$-mobilizing physiological (bradykinin) and nonphysiological (A23187) agonists elicit CK-II-dependent cPGES activation.

It is well recognized that anti-inflammatory glucocorticoids suppress delayed $\mathrm{PGE}_{2}$ production by attenuating the inducible expression of COX-2 and mPGES-1 [3,6-8]. In the present study, we show that dexamethasone ameliorates cPGES activation (i.e. immediate $\mathrm{PGE}_{2}$ generation) through a post-translational mechanism, most likely through preventing cPGES phosphorylation by CK-II. Since glucocorticoids inhibit p38 activation [29-31], it is reasonable to consider that the dexamethasone effect observed here resulted from the inhibition of the $\mathrm{p} 38$ pathway and thereby downstream CK-II and cPGES. It is also possible that the active cPGES-CK-II-Hsp90 complex contains an additional regulatory component that is sensitive to dexamethasone, which remains to be addressed.

In summary, we propose that functional cPGES exists in cells as a multicomponent complex that also contains CK-II and Hsp90 as the minimal requirements. In cells under normal culture conditions, only a small fraction of the cellular cPGES pool (latent form) is complexed with CK-II and Hsp90 and undergoes steadystate phosphorylation possibly through serum stimulation. CK-II activated by upstream signals triggers dual phosphorylation of $\mathrm{Ser}^{113}$ and $\mathrm{Ser}^{118}$ on cPGES, which in turn promotes the recruitment of cPGES into the Hsp90 complex, leading to its full activation. It is possible that additional Hsp90 client protein(s) may play some regulatory roles in the formation of the tertiary complex. It is notable that, after bradykinin stimulation, cPGES-CKII-Hsp90 complex formation and the resulting cPGES phosphorylation occurred only transiently. Since CK-II can be associated with protein phosphatase 2A [53], dephosphorylation of CK-II and/or cPGES by this phosphatase might contribute to termination of the cPGES-activating signals. No matter what mechanisms are involved in the triggering of formation and sequestration of the cPGES-CK-II-Hsp90 tertiary complex, our present results have provided, to the best of our knowledge, the first evidence that the function of terminal PGES is elegantly controlled by a particular protein kinase in co-operation with a molecular chaperone.
This work was supported by grants-in-aid for scientific research from the Ministry of Education, Science, Culture, Sports and Technology of Japan.

\section{REFERENCES}

1 Kudo, I. and Murakami, M. (2002) Phospholipase $A_{2}$ enzymes. Prostaglandins Other Lipid Mediat. 68-69, 3-58

2 Murakami, M. and Kudo, I. (2001) Diversity and regulatory functions of mammalian secretory phospholipase A, S. Adv. Immunol. 77, 163-194

3 Smith, W. L., DeWitt, D. L. and Garavito, R. M. (2000) Cyclooxygenases: structural, cellular, and molecular biology. Annu. Rev. Biochem. 69, 145-182

4 Murakami, M., Kambe, T., Shimbara, S. and Kudo, I. (1999) Functional coupling between various phospholipase $\mathrm{A}_{2} \mathrm{~S}$ and cyclooxygenases in immediate and delayed prostanoid biosynthetic pathways. J. Biol. Chem. 274, 3103-3115

5 Smith, W. L. and Langenbach, R. (2001) Why there are two cyclooxygenase isozymes J. Clin. Invest. 107, 1491-1495

6 Jakobsson, P. J., Thoren, S., Morgenstern, R. and Samuelsson, B. (1999) Identification of human prostaglandin E synthase: a microsomal, glutathione-dependent, inducible enzyme, constituting a potential novel drug target. Proc. Natl. Acad. Sci. U.S.A. 96 7220-7225

7 Mancini, J. A., Blood, K., Guay, J., Gordon, R., Claveau, D., Chan, C. C. and Riendeau, D. (2001) Cloning, expression, and up-regulation of inducible rat prostaglandin $E$ synthase during lipopolysaccharide-induced pyresis and adjuvant-induced arthritis. J. Biol. Chem. 276, 4469-4475

8 Murakami, M., Naraba, H., Tanioka, T., Semmyo, N., Nakatani, Y., Kojima, F., Ikeda, T., Fueki, M., Ueno, A., Oh-Ishi, S. and Kudo, I. (2000) Regulation of prostaglandin $E_{2}$ biosynthesis by inducible membrane-associated prostaglandin $\mathrm{E}_{2}$ synthase that acts in concert with cyclooxygenase-2. J. Biol. Chem. 275, 32783-32792

9 Tanikawa, N., Ohmiya, Y., Ohkubo, H., Hashimoto, K., Kangawa, K., Kojima, M., Ito, S. and Watanabe, K. (2002) Identification and characterization of a novel type of membrane-associated prostaglandin E synthase. Biochem. Biophys. Res. Commun. 291, 884-889

10 Tanioka, T., Nakatani, Y., Semmyo, N., Murakami, M. and Kudo, I. (2000) Molecular identification of cytosolic prostaglandin $E_{2}$ synthase that is functionally coupled with cyclooxygenase- 1 in immediate prostaglandin $\mathrm{E}_{2}$ biosynthesis. J. Biol. Chem. 275 , 32775-32782

11 Stichtenoth, D. O., Thoren, S., Bian, H., Peters-Golden, M., Jakobsson, P. J. and Crofford, L. J. (2001) Microsomal prostaglandin E synthase is regulated by proinflammatory cytokines and glucocorticoids in primary rheumatoid synovial cells. J. Immunol. 167 469-474

12 Yamagata, K., Matsumura, K., Inoue, W., Shiraki, T., Suzuki, K., Yasuda, S., Sugiura, H., Cao, C., Watanabe, Y. and Kobayashi, S. (2001) Coexpression of microsomal-type prostaglandin $\mathrm{E}$ synthase with cyclooxygenase-2 in brain endothelial cells of rats during endotoxin-induced fever. J. Neurosci. 21, 2669-2677

13 Kamei, D., Murakami, M., Nakatani, Y., Ishikawa, Y., Ishii, T. and Kudo, I. (2003) Potential role of microsomal prostaglandin E synthase-1 in tumorigenesis. J. Biol. Chem. 278, 19396-19405

14 Uematsu, S., Matsumoto, M., Takeda, K. and Akira, S. (2002) Lipopolysaccharidedependent prostaglandin $\mathrm{E}_{2}$ production is regulated by the glutathione-dependent prostaglandin $E_{2}$ synthase gene induced by the Toll-like receptor 4/MyD88/NF-IL6 pathway. J. Immunol. 168, 5811-5816

15 Trebino, C. E., Stock, J. L., Gibbons, C. P., Naiman, B. M., Wachtmann, T. S., Umland, J. P., Pandher, K., Lapointe, J. M., Saha, S., Roach, M. L. et al. (2003) Impaired inflammatory and pain responses in mice lacking an inducible prostaglandin $E$ synthase. Proc. Natl. Acad. Sci. U.S.A. 100, 9044-9049

16 Naraba, H., Yokoyama, C., Tago, N., Murakami, M., Kudo, I., Fueki, M., Oh-Ishi, S. and Tanabe, T. (2002) Transcriptional regulation of the membrane-associated prostaglandin $E_{2}$ synthase gene: essential role of the transcription factor Egr-1. J. Biol. Chem. 277, 28601-28608

17 Murakami, M., Nakashima, K., Kamei, D., Masuda, S., Ishikawa, Y., Ishii, T., Ohmiya, Y., Watanabe, K. and Kudo, I. (2003) Cellular prostaglandin $E_{2}$ production by membrane-bound prostaglandin E synthase-2 via both cyclooxygenases-1 and -2 . J. Biol. Chem. 278, 37937-37947

18 Tanioka, T., Nakatani, Y., Kobayashi, T., Tsujimoto, M., Oh-ishi, S., Murakami, M. and Kudo, I. (2003) Regulation of cytosolic prostaglandin $E_{2}$ synthase by $90-k D a$ heat shock protein. Biochem. Biophys. Res. Commun. 303, 1018-1023

19 Miyata, Y., Chambraud, B., Radanyi, C., Leclerc, J., Lebeau, M. C., Renoir, J. M., Shirai, R., Catelli, M. G., Yahara, I. and Baulieu, E. E. (1997) Phosphorylation of the immunosuppressant FK506-binding protein FKBP52 by casein kinase II: regulation of HSP90-binding activity of FKBP52. Proc. Natl. Acad. Sci. U.S.A. 94, 14500-14505

20 Miyata, Y. and Yahara, I. (1995) Interaction between casein kinase II and the 90-kDa stress protein, HSP90. Biochemistry 34, 8123-8129 
21 Kuwata, H., Nakatani, Y., Murakami, M. and Kudo, I. (1998) Cytosolic phospholipase A is required for cytokine-induced expression of type IIA secretory phospholipase $A_{2}$ that mediates optimal cyclooxygenase-2-dependent delayed prostaglandin $\mathrm{E}_{2}$ generation in rat 3 Y1 fibroblasts. J. Biol. Chem. 273, 1733-1740

22 Cosmelli, D., Antonelli, M., Allende, C. C. and Allende, J. E. (1997) An inactive mutant of the $\alpha$ subunit of protein kinase CK2 that traps the regulatory CK2 $\beta$ subunit. FEBS Lett. 410, 391-396

23 Qiu, Z. H. and Leslie, C. C. (1994) Protein kinase C-dependent and -independent pathways of mitogen-activated protein kinase activation in macrophages by stimuli that activate phospholipase A2. J. Biol. Chem. 269, 19480-19487

24 Muthalif, M. M., Hefner, Y., Canaan, S., Harper, J., Zhou, H., Parmentier, J. H., Aebersold, R., Gelb, M. H. and Malik, K. U. (2001) Functional interaction of calcium-/calmodulin-dependent protein kinase II and cytosolic phospholipase $\mathrm{A}_{2}$. J. Biol. Chem. 276, 39653-39660

25 Hrubey, T. W. and Roach, P. J. (1990) Phosphoserine in peptide substrates can specify casein kinase II action. Biochem. Biophys. Res. Commun. 172, 190-196

26 Marin, 0., Meggio, F., Draetta, G. and Pinna, L. A. (1992) The consensus sequences for cdc2 kinase and for casein kinase-2 are mutually incompatible. A study with peptides derived from the $\beta$-subunit of casein kinase-2. FEBS Lett. 301, 111-114

27 Sayed, M., Kim, S. O., Salh, B. S., Issinger, O. G. and Pelech, S. L. (2000) Stress-induced activation of protein kinase CK2 by direct interaction with p38 mitogen-activated protein kinase. J. Biol. Chem. 275, 16569-16573

28 Kato, Jr, T., Delhase, M., Hoffmann, A. and Karin, M. (2003) CK2 is a C-terminal $I_{\kappa} B$ kinase responsible for $\mathrm{NF}-\kappa \mathrm{B}$ activation during the UV response. Mol. Cell 12, 829-839

29 Lasa, M., Abraham, S. M., Boucheron, C., Saklatvala, J. and Clark, A. R. (2002) Dexamethasone causes sustained expression of mitogen-activated protein kinase (MAPK) phosphatase 1 and phosphatase-mediated inhibition of MAPK p38. Mol. Cell. Biol. 22, 7802-7811

30 Jeong, H. J., Na, H. J., Hong, S. H. and Kim, H. M. (2003) Inhibition of the stem cell factor-induced migration of mast cells by dexamethasone. Endocrinology 144 , 4080-4086

31 Subbaramaiah, K., Marmo, T. P., Dixon, D. A. and Dannenberg, A. J. (2003) Regulation of cyclooxgenase-2 mRNA stability by taxanes: evidence for involvement of $p 38$, MAPKAPK-2 and HuR. J. Biol. Chem. 278, 37637-37647

32 Lin, L. L., Wartmann, M., Lin, A. Y., Knopf, J. L., Seth, A. and Davis, R. J. (1993) cPLA 2 is phosphorylated and activated by MAP kinase. Cell 72, 269-278

33 Hefner, Y., Borsch-Haubold, A. G., Murakami, M., Wilde, J. I., Pasquet, S., Schieltz, D., Ghomashchi, F., Yates, 3rd, J. R., Armstrong, C. G., Paterson, A. et al. (2000) Serine 727 phosphorylation and activation of cytosolic phospholipase $A_{2}$ by MNK1-related protein kinases. J. Biol. Chem. 275, 37542-37551

34 Werz, O., Burkert, E., Fischer, L., Szellas, D., Dishart, D., Samuelsson, B., Radmark, 0. and Steinhilber, D. (2002) Extracellular signal-regulated kinases phosphorylate 5-lipoxygenase and stimulate 5-lipoxygenase product formation in leukocytes. FASEB J. 16, 1441-1443

35 Werz, 0., Szellas, D., Steinhilber, D. and Radmark, 0. (2002) Arachidonic acid promotes phosphorylation of 5-lipoxygenase at Ser-271 by MAPK-activated protein kinase 2 (MK2). J. Biol. Chem. 277, 14793-14800

36 Han, R., Tsui, S. and Smith, T. J. (2002) Up-regulation of prostaglandin $E_{2}$ synthesis by interleukin- $1 \beta$ in human orbital fibroblasts involves coordinate induction of prostaglandin-endoperoxide $H$ synthase-2 and glutathione-dependent prostaglandin $E_{2}$ synthase expression. J. Biol. Chem. 277, 16355-16364

Received 21 January 2004/24 March 2004; accepted 25 March 2004

Published as BJ Immediate Publication 25 March 2004, D0I 10.1042/BJ20040118
37 Guo, Y. S., Hellmich, M. R., Wen, X. D. and Townsend, Jr, C. M. (2001) Activator protein-1 transcription factor mediates bombesin-stimulated cyclooxygenase-2 expression in intestinal epithelial cells. J. Biol. Chem. 276, 22941-22947

38 Ogasawara, A., Arakawa, T., Kaneda, T., Takuma, T., Sato, T., Kaneko, H., Kumegawa, M. and Hakeda, Y. (2001) Fluid shear stress-induced cyclooxygenase-2 expression is mediated by $\mathrm{C} / \mathrm{EBP} \beta$, CAMP-response element-binding protein, and AP-1 in osteoblastic MC3T3-E1 cells. J. Biol. Chem. 276, 7048-7054

39 Sullivan, W. P., Owen, B. A. and Toft, D. 0. (2002) The influence of ATP and p23 on the conformation of hsp90. J. Biol. Chem. 277, 45942-45948

40 Freeman, B. C., Felts, S. J., Toft, D. 0. and Yamamoto, K. R. (2000) The p23 molecular chaperones act at a late step in intracellular receptor action to differentially affect ligand efficacies. Genes Dev. 14, 422-434

41 Hutchison, K. A., Stancato, L. F., Owens-Grillo, J. K., Johnson, J. L., Krishna, P., Toft, D. 0. and Pratt W. B. (1995) The 23-kDa acidic protein in reticulocyte lysate is the weakly bound component of the hsp foldosome that is required for assembly of the glucocorticoid receptor into a functional heterocomplex with hsp90. J. Biol. Chem. 270, 18841-18847

42 Weaver, A. J., Sullivan, W. P., Felts, S. J., Owen, B. A. and Toft, D. 0. (2000) Crystal structure and activity of human p23, a heat shock protein 90 co-chaperone. J. Biol. Chem. 275, 23045-23052

43 Meyer, P., Prodromou, C., Hu, B., Vaughan, C., Roe, S. M., A Panaretou, B., Piper, P. W. and Pearl, L. H. (2003) Structural and functional analysis of the middle segment of hsp90: implications for ATP hydrolysis and client protein and cochaperone interactions. Mol. Cell 11, 647-658

44 Ahmed, K., Gerber, D. A. and Cochet, C. (2002) Joining the cell survival squad: an emerging role for protein kinase CK2. Trends Cell Biol. 12, 226-230

45 Meek, D. W., Simon, S., Kikkawa, U. and Eckhart, W. (1990) The p53 tumour suppressor protein is phosphorylated at serine 389 by casein kinase II. EMBO J. $\mathbf{9}$, 3253-3260

46 Hupp, T. R., Meek, D. W., Midgley, C. A. and Lane, D. P. (1992) Regulation of the specific DNA binding function of $p 53$. Cell 71, 875-886

47 Blaydes, J. P. and Hupp, T. R. (1998) DNA damage triggers DRB-resistant phosphorylation of human p53 at the CK2 site. Oncogene 17, 1045-1052

48 Wang, D., Westerheide, S. D., Hanson, J. L. and Baldwin, Jr, A. S. (2000) Tumor necrosis factor $\alpha$-induced phosphorylation of RelA/p65 on $\operatorname{Ser}^{529}$ is controlled by casein kinase II. J. Biol. Chem. 275, 32592-32597

49 Lin, R., Beauparlant, P., Makris, C., Meloche, S. and Hiscott, J. (1996) Phosphorylation of $I_{\kappa} \mathrm{B} \alpha$ in the $\mathrm{C}$-terminal PEST domain by casein kinase $\|$ affects intrinsic protein stability. Mol. Cell. Biol. 16, 1401-1409

50 Song, D. H., Sussman, D. J. and Seldin, D. C. (2000) Endogenous protein kinase CK2 participates in Wnt signaling in mammary epithelial cells. J. Biol. Chem. 275 , 23790-23797

51 Desagher, S., Osen-Sand, A., Montessuit, S., Magnenat, E., Vilbois, F., Hochmann, A., Journot, L., Antonsson, B. and Martinou, J. C. (2001) Phosphorylation of bid by casein kinases I and II regulates its cleavage by caspase 8 . Mol. Cell 8, 601-611

52 Blanquet, P. R. (2000) Identification of two persistently activated neurotrophin-regulated pathways in rat hippocampus. Neuroscience 86, 739-749

53 Lebrin, F., Bianchini, L., Rabilloud, T., Chambaz, E. M. and Goldberg, Y. (1999) CK2 $\alpha$ protein phosphatase $2 A$ molecular complex: possible interaction with the MAP kinase pathway. Mol. Cell. Biochem. 191, 207-212 